JOB \#: 169342

Author Name: Jin

Title of Book: The Culture of Power

ISBN: 9780804735292

Publisher: Stanford Univ. Press

Trim Size: 6 x 9

Bulk in mm: 17 

THE CULTURE OF POWER

The Lin Biao Incident in the

Cultural Revolution 

JIN QIU

\section{The Culture of Power}

The Lin Biao Incident in the Cultural Revolution

STANFORD UNIVERSITY PRESS

STANFORD, CALIFORNIA 
Stanford University Press

Stanford, California

(C) 1999 by the Board of Trustees of the

Leland Stanford Junior University

Printed in the United States of America

CIP data appear at the end of the book 
To my parents,

my brother and sisters, and all those who

suffered unduly 
